\title{
Grupo de familiares acompanhantes de pacientes hospitalizados: estratégia de intervençáo da Terapia Ocupacional em um hospital geral
}

\author{
Daniel Ferreira Dahdaha ${ }^{\mathrm{a}}$ Ana Maria Pimenta Carvalho ${ }^{\mathrm{b}}$, \\ Juliana Carla Delsimc, Bruna Romano Gomes ${ }^{\mathrm{d}}$, Vanessa Spera de Miguel ${ }^{\mathrm{d}}$
}

${ }^{a}$ Mestre em Ciências pelo Programa de Enfermagem Psiquiátrica e Ciências Humanas da Escola de Enfermagem de Ribeirão Preto/USP; Terapeuta ocupacional do Hospital Estadual de Ribeirão Preto, Ribeirão Preto, SP, Brasil ${ }^{b}$ Professora Doutora do Departamento de Enfermagem Psiquiátrica e Ciências Humanas, Escola de Enfermagem de Ribeirão Preto, Universidade de São Paulo - USP, Ribeirão Preto, SP, Brasil

${ }^{\mathrm{c}}$ Mestre em Ciências pelo Programa de Pós-graduação Interunidades em Bioengenharia, Escola de Engenharia de São Carlos; Terapeuta ocupacional do Hospital Estadual de Ribeirão Preto, Ribeirão Preto, SP, Brasil

dTerapeuta ocupacional pela Faculdade de Medicina de Ribeirão Preto/ USP-RP, Ribeirão Preto, SP, Brasil

\begin{abstract}
Resumo: É consenso na literatura que a presença de um familiar acompanhante durante o período de internação é um fator potencializador da recuperação do paciente. Apesar de ser positivo para o doente, a permanência no hospital do familiar acompanhante traz consigo algumas implicações para a vida e para a saúde dessa pessoa. Com o objetivo de minimizar os efeitos negativos do papel de cuidado, promover acolhimento e possibilitar espaço para o familiar acompanhante se expressar é realizado o grupo de acompanhantes familiares do Hospital Estadual de Ribeirão Preto, coordenado pelo Serviço de Terapia Ocupacional. O foco principal do artigo é discutir a atenção oferecida no ambiente de um hospital geral aos familiares que acompanham todo o processo de adoecimento e hospitalização do integrante de sua família e sofrem os impactos dessa ação em todo o seu cotidiano. E em especial a intervenção terapêutica ocupacional com esse público.
\end{abstract}

Palavras-chave: Família, Processos grupais, Terapia Ocupacional.

\section{Group of family companions of hospitalized patients: an occupational therapy intervention strategy in a general hospital}

\begin{abstract}
There is a consensus in the literature that the company of a family member during the hospitalization period increases patient recovery. However, this can have some negative effects on the caregiver's health. With the purpose of reducing these negatives effects, it is useful to let family members express themselves. The State Hospital of Ribeirão Preto created a Group of Family Companions coordinated by the Occupational Therapy and Social Service. This study focuses on the assistance offered in a general hospital to families that undergo the whole illness and hospitalization process of their family member, suffering the impacts of this process in their daily lives, and on the intervention of Occupational Therapy in these cases.
\end{abstract}

Keywords: Family, Group Processes, Occupational Therapy. 


\section{Introdução}

O hospital tal como o conhecemos hoje é uma invenção moderna que ao longo do tempo sofreu e sofre muitas transformaçóes. No entanto, mesmo com as mudanças no caráter e objetivos da instituição hospitalar, esse espaço permaneceu com característica de disciplinador (a disciplina dos corpos, comportamentos e pensamentos) e caritativo (representação de que os profissionais que nele trabalham o fazem por desprendimento e caridade). Assim, para que essa disciplinarizaçáo se efetive, o doente é "infantilizado", tornando-o submisso e melhor controlado e a organizaçáo dos cuidados é feita através da racionalização de serviços, da organização do espaço, do controle dos comportamentos e das restriçôes das atividades. Isso porque os objetivos dessa instituição são totalmente medicalizados, visto que a função primordial passou a ser a de manutenção das condições biológicas essenciais para a sobrevivência humana e recuperação da saúde orgânica (DE CARLO et al., 2006).

Iniciou-se nas últimas décadas uma mobilizaçấo dos profissionais de saúde sob as diretrizes de humanização da assistência a facilitação do acesso de familiares ao cuidado de seus parentes no ambiente hospitalar, entendendo que a permanência da família como colaboradora facilita o processo de recuperaçáo da saúde para o sujeito internado (DIBAI; CADE, 2009).

Os autores afirmam ainda que as unidades de internação hospitalar enfrentam dificuldades ou estão iniciando sua estruturação quanto à organização da assistência no que tange à permanência da família nesse ambiente institucional e a sua participação no tratamento, bem como a natureza da relação entre familiares e profissionais de saúde.

É válido ressaltar como apontado acima que a (re) estruturaçáo do ambiente hospitalar deve envolver a própria estrutura física e também a organização das relaçóes. São várias as situações em que a própria estrutura física hospitalar não favorece a permanência do familiar na unidade de internação e em que a equipe de saúde nem sempre se mostra acolhedora à família, que vivencia, muitas vezes, um processo de intenso sofrimento. Além disso, é clara a dificuldade que os profissionais de saúde apresentam para incluir a família em seu plano de cuidados, reconhecendo-a como parte integrante da vida de um adulto ou idoso perante o difícil processo de hospitalização (BOCCHI et al., 2007; SILVA; BOCCHI; BOUSSO, 2008).
Existe uma dificuldade da equipe de saúde em dizer que cuida da família, além de cuidar do paciente. Ninguém, no contexto hospitalar, diz que é responsável pela família do paciente. Com isso, a família fica desamparada, sem um suporte adequado e tendo ignorados pela equipe os riscos de doenças físicas, a diminuição da atenção, a irritabilidade e o comprometimento na capacidade de decisão, fatores que interferem diretamente na habilidade de entender políticas, rotinas e procedimentos do hospital, que poderiam parecer lógicos e racionais para a equipe (ROMANO, 1997).

Mesmo com toda a dificuldade da equipe e das instituiçóes em promover a aproximação famíliahospital-tratamento, é consenso na literatura que a presença de um familiar acompanhante durante o período de internação é de extrema importância pra o paciente, além de potencializar a sua melhora. Assim, a presença dos familiares não é uma boa ação realizada pelos hospitais, mas sim uma necessidade para o auxílio da terapêutica do paciente. Além disso, referem que a presença de uma pessoa da convivência do paciente influencia positivamente no comportamento dele, além de oferecer conforto e suporte emocional durante essa fase em que vivencia um momento crítico da vida (LAUTERT; ECHER; UNICOVSKY, 1998).

Se, por um lado, a presença do familiar acompanhante é um fator positivo para o doente, ela traz consigo algumas implicaçóes para a vida e para a saúde desse familiar que acompanha, visto que o cuidado não é uma tarefa fácil, pois envolve lidar com os limites humanos, com a vida, com a doença e com a própria morte, elementos que rondam, constantemente, o cenário hospitalar (DIBAI; CADE, 2009).

O familiar acompanhante do doente na hospitalização muitas vezes apresenta-se fragilizado na sua totalidade, situação decorrente dos longos períodos sem revezamento com outros familiares nesse papel. Por conseguinte, ele é, em geral, privado da possibilidade de desenvolver açóes em prol de seu autocuidado e de compartilhar sentimentos de medo e de angústia em relação ao doente com os outros membros da família, principalmente nos casos em que esse se encontra em estado crítico de vida (CHAGAS; MONTEIRO, 2004; FRANCO; JORGE, 2002).

Mesmo vivenciando toda essa situação estressante e angustiante, o familiar deseja se tornar familiar acompanhante por vários motivos: insegurança, interesse no paciente, sentimento de corresponsabilidade pela recuperação do paciente, oportunidade de aprender, obrigação, respeito 
e simplesmente para estar junto (ANDRADE; MARCON; SILVA, 1997).

A soma dessas três perspectivas (melhora da qualidade da internaçáo para o paciente, interesse do familiar em ser acompanhante e a permissão da instituição) trouxe novas exigências para as equipes de saúde e para o próprio ambiente hospitalar.

Nesse contexto, iniciaram-se os atendimentos terapêutico-ocupacionais aos acompanhantes. A partir do exposto, o artigo busca relatar a experiência dos autores na conduçáo de grupos de acolhimento e suporte emocional de acompanhantes familiares no período de internação do ente em cuidado no Hospital Estadual de Ribeirão Preto.

\section{Descrição da experiência}

O local: As atividades foram são desenvolvidas no Hospital Estadual de Ribeirão Preto, SP, um hospital de média complexidade. O tratamento é clínico, atendendo as características do nível secundário e também inclui consultas ambulatoriais e cirurgias que se enquadram no perfil do hospital. As atividades do grupo são desenvolvidas com familiares dos pacientes internados nas enfermarias, compostas por duas alas, cada uma com 25 leitos (12 quartos comuns e 1 quarto para isolamento).

Estruturaçáo do serviço: O Serviço de Terapia Ocupacional é formado por dois terapeutas ocupacionais e tem cobertura diária de 12 horas, com exceção dos sábados e feriados, com cobertura de seis horas, e sem atendimentos aos domingos.

A atenção da Terapia Ocupacional estrutura-se através de programas de atendimento, sendo o programa de atenção a familiares um deles. Nesse programa, são desenvolvidas principalmente três açóes: o atendimento individual a familiares, com o objetivo de acolher as demandas psicoafetivas, emocionais e sociais deles; o atendimento interdisciplinar às famílias, com objetivo de auxiliar na organizaçáo dos cuidados a partir de um olhar interdisciplinar, e o grupo de família, alvo de nossa atenção no presente artigo.

Todos aqueles acompanhantes que se encontram no hospital no horário em que o grupo acontece são convidados a participar da vivência e as intervenções acontecem desde o primeiro contato dos profissionais com os acompanhantes familiares.

Os participantes dos grupos: Os participantes são em geral mulheres de meia idade. Poucos homens participaram do grupo, o que remete a pensar no cuidado como uma tarefa historicamente construída para ser feminina. Como o hospital recebe um número grande de idosos, as filhas deles são as acompanhantes mais frequentes. Também se encontram cônjuges, mães, sobrinhos(as), noras e genros e cunhados(as). O grau de parentesco nesse momento não é o mais importante e sim a afinidade entre o acompanhante e o paciente.

Observa-se em alguns casos certa resistência para deixar o paciente e participar do grupo. Tal resistência é justificada por medo de deixar o paciente sozinho, medo de o médico chegar e não conseguir as informaçôes sobre o quadro clínico ou receio de que algo "ruim" aconteça. Esses sentimentos são acolhidos no momento em que aparecem. A seguir organiza-se com a equipe de enfermagem a assistência ao paciente no momento em que o familiar participa do grupo, minimizando as preocupaçóes e sensibilizando o acompanhante sobre a importância do momento de olhar para si enquanto uma pessoa que também tem necessidades.

As etapas de preparaçáo e desenvolvimento do grupo: A partir do entendimento do papel do acompanhante no hospital e de todo o processo que ele vivencia dentro dessa instituição, os objetivos dos grupos são: promover o acolhimento, possibilitar a existência de um espaço para a expressão de afeto, incentivar a organizaçáo da rotina de cuidados, auxiliar na elaboração de estratégias que minimizem os danos do desempenhar esse papel e incentivar atividades que valorizem o prazer e o autocuidado.

Trata-se de um grupo aberto e heterogêneo. Já a sua classificação pode oscilar de acordo com o momento do grupo, com a quantidade de participantes e o espaço físico para o seu desenvolvimento. Assim, podem ser classificados como: grupo tarefa-orientado (projetado para ajudar os integrantes a tornarem-se conscientes das suas necessidades, valores, ideias e sentimentos, conforme influenciam suas ações) ou grupo temático (com foco no aumento do conhecimento, das habilidades e das atitudes necessárias para o domínio de componentes do desempenho e desempenhos ocupacionais específicos). Também oscilam quanto à sua divisão: em determinados momentos são grupos de atividades e, em outros, grupos de atividade grupal (MOSEY, 1986 apud HAGEDORN, 2007).

Com o setting terapêutico pronto, inicia-se o convite nos quartos das enfermarias. Esse primeiro contato ocorre minutos antes de se iniciar o grupo. É neste momento que o profissional pode iniciar o estabelecimento do vínculo, buscando identificar como se deu a escolha dessa pessoa para se tornar o acompanhante familiar, na tentativa de caracterizar as motivaçóes presentes para o desempenho desse papel, visto que elas são preditoras, tanto de situaçóes positivas, como o suporte integral ao doente, quanto de situaçóes adversas, como a presença de maus-tratos e de desorganização familiar. 
Diante dos objetivos e da constituição do grupo, seleciona-se uma atividade a fim de alcançá-los. Essa atividade tem um papel de disparador e facilitador da comunicação, possibilitando a discussão sobre as dificuldades de permanência no hospital e os impactos dessa vivência na vida cotidiana dos familiares acompanhantes.

Nos grupos são realizadas basicamente atividades expressivas, produtivas, corporais e de lazer. As primeiras sáo utilizadas com o intuito de acessar os conteúdos internos dos participantes pela concretização dos sentimentos não expressos pela fala. Sáo exemplos desse segmento a colagem, a pintura, a escrita, entre outras. Já as atividades produtivas (decóupage em madeira, bijuteria, pintura em tecido etc.) têm como objetivo a retomada do sentimento de utilidade e a motivaçáo dos participantes que, através do fazer, descobrem novos caminhos para solucionar os problemas enfrentados. As atividades corporais são aquelas em que o corpo é o objetivo e o objeto da intervenção, possibilitando voltar o olhar do participante para o seu próprio corpo e para a sua saúde, ressaltando a necessidade do autocuidado, sendo os alongamentos e os relaxamentos bons exemplos dessas atividades. O lazer, tâo discutido na atualidade, é utilizado na tentativa de minimizar os sentimentos negativos através de atividades que sejam agradáveis, contribuindo para reafirmar a importância do cuidado consigo.

O desenvolvimento do grupo é direcionado pelo coordenador, que tem papel de facilitador e explorador dos sentimentos verbalizados e/ou exteriorizados através do fazer. Todos no grupo têm direito à voz, se assim desejarem. A livre interpretação da atividade é estimulada pelo terapeuta e compartilhada com o grupo. Após essa etapa, o terapeuta inicia o processo de finalização do grupo, permitindo que cada um exponha sua última mensagem aos demais participantes, fazendo uma avaliação geral do que foi experienciado. Ao final de cada grupo, os familiares têm a oportunidade de fazerem uma avaliaçáo do grupo, dos seus sentimentos e da sua participaçáo.

Resultados e discussáo: A utilizaçáo de atividades no grupo possibilita criar meios de manejo do estresse vivenciado pelo familiar acompanhante no ambiente intra e extra-hospitalar, além de permitir conhecer e intervir na realidade vivida pelo participante do grupo.

Como a atividade é intrinsecamente ligada à Terapia Ocupacional, no grupo ela é utilizada com o objetivo de afetar o sujeito, conectando-o com o ambiente através dos órgãos do sentido. $\mathrm{O}$ grupo pode ser visto como um elemento que amplia essa característica, fazendo ressoar os sentimentos despertados. Dessa forma, a verticalidade de cada participante vai aos poucos se construindo como horizontalidade, favorecendo as trocas e a aprendizagem de novas formas de fazer e se relacionar (MAXIMINO, 2001).

Através da tarefa proposta ao grupo são elucidadas as ansiedades comuns aos participantes, mas que se manifestam de diferentes maneiras em cada um deles. Com essa dinâmica, quebra-se o funcionamento estereotipado e o grupo consegue chegar à comunicação e à aprendizagem (PICHONRIVIÉRE, 2005).

Nesse sentido, a experiência na condução desses grupos permite afirmar que nesse contexto e junto a essa população o atendimento grupal é uma das técnicas mais eficazes para atingir os objetivos propostos, uma vez que a ideia do grupo é criar um ambiente propício à exteriorização dos sentimentos dos participantes. É nesse setting que seus integrantes podem compartilhar suas experiências com a certeza de que são profundamente compreendidos pelos outros. Os encontros, as discussóes e o próprio grupo proporcionam o combate ao isolamento social, a universalidade e o apoio necessário aos seus integrantes (VINOGRADOV; YALOM, 1992).

Durante a participação em grupos, as pessoas vivem muitas experiências significativas que podem mudar sua compreensão dos fatos da vida e ajudar no enfrentamento de problemas através da aquisição de atitudes mais saudáveis. Essas mudanças são possíveis porque intragrupo acontecem mecanismos denominados "fatores curativos". A ocorrência deles permite avaliar a eficiência do atendimento grupal na proposição de experiências com valor terapêutico aos seus participantes (YALOM; LESZCZ, 2006).

Partindo do entendimento dos fatores curativos descritos por Vinogradov e Yalom (1992), analisou-se a dinâmica do grupo.

Assim, pode-se observar falas de gratidão pela possibilidade de compartilhar com os outros a experiência pessoal, fomentando atitudes altruístas. O altruísmo é um importante fator curativo, visto que também possibilita a diminuição dos sentimentos de isolamento e solidão.

Outros fatores curativos podem ser visualizados, como, por exemplo, a universalidade, que acontece quando o familiar identifica que a situaçẫo vivenciada por ele é a mesma das outras pessoas, permitindo que os membros do grupo percebam náo serem os únicos a viver um problema. É através desse compartilhamento de experiências que os integrantes entendem que a situaçáo ou sentimentos que vivem também são experimentados por outros, o que facilita a comunicação de sentimentos negativos como culpa ou inadequaçáo no enfrentamento de situaçôes problemas. Ao notar que os demais também procuram soluçóes, o familiar sente-se aliviado por 
poder descarregar o peso e saber que outras pessoas estáo abertas e disponíveis para compartilhar uma experiência parecida.

Em seguida, e intimamente ligado à universalidade, observa-se a instilação de esperança. Como o grupo é heterogêneo em vários aspectos, pode-se observar variadas experiências, que ao serem expostas no grupo alimentam as esperanças dos seus integrantes. É comum ouvir no grupo falas de pessoas mais experientes encorajando as recém-chegadas ao hospital, possibilitando a ressignificaçáo dos sentimentos e a minimização de angústia e da ansiedade desses últimos.

Tal situação possibilita a aprendizagem interpessoal, um fator curativo que se sobrepóe aos outros. O grupo oferece aos participantes a chance de realizar mudanças em seu comportamento pessoal, clarear as dificuldades, encontrar alternativas para enfrentar os problemas e experimentar novos comportamentos a partir da vivência exposta pelo outro. É a oportunidade de aprender com alguém que já vivenciou uma situação semelhante a melhor forma de transpor o desafio. Os participantes do grupo comumente referem que encontraram formas mais adequadas de enfrentamento de problemas após os encontros.

O grupo também é um espaço em que se possibilita o oferecimento de informaçôes, permitindo a clarificação e a soluçáo de dificuldades relacionadas à organização da rotina hospitalar, além de situaçôes conflitantes com a equipe. O hospital é um espaço peculiar e intimidador, com uma rotina única. $\mathrm{O}$ familiar, ao adentrar nesse contexto, sente, junto com o paciente, os impactos na rotina e na organização dos cuidados. Diversos questionamentos emergem no grupo e são esclarecidos pelo coordenador, visto que possibilitam minimamente o sentimento de pertencimento ao espaço, minimizando situaçóes de conflito, principalmente com a equipe de cuidados. Nota-se também a melhora na assertividade, tornando as relações mais efetivas e a comunicação mais eficaz.

A catarse é outro fator curativo experienciado pelos integrantes dos grupos. A possibilidade de falar sobre angústias, medos e dramas em um espaço em que todos compartilham desses mesmos sentimentos permite ao familiar modificar padróes estereotipados e elaborar estratégias que permitam a liberdade diante de algumas situaçôes opressoras.

Por fim, a experiência de compartilhar todos esses fatores curativos, dentro de um ambiente pouco permissivo e onde vários tabus relacionados à existência humana se conflitam, surge a possibilidade colocar em cheque a própria existência, configurando um fator curativo. É nesse momento que os integrantes do grupo percebem que por mais ajuda que recebam, são eles que devem se responsabilizar pelas próprias vidas e escolhas. Normalmente, o coordenador do grupo os leva a refletirem sobre tal fato, na tentativa de que eles próprios funcionem como organizadores do cuidado ao ente adoecido e consigam equilibrar responsabilidades e tarefas, tornando o cuidado mais prazeroso, ao invés de torná-lo um fardo.

\section{Considerações finais e implicações para a prática}

Muitas mudanças na família vêm ocorrendo na sua organização, formação, estruturação e objetivos. Além disso, são várias as perspectivas de que se pode olhar para ela. Na prática clínica, se faz necessário entender quem o paciente reconhece como integrante da sua família, a quem ele atribui o papel de familiar e os laços que ele estabelece com cada membro.

Tal conhecimento permite à equipe de saúde estabelecer uma rede de suporte a este acompanhante, na tentativa de que todas as necessidades do doente sejam supridas, na tentativa de sempre minimizar o desgaste ou sobrecarga dos familiares.

Deve-se levar em conta que o papel ocupacional de cuidador soma-se a outros que, mesmo com desempenho deficitário, não deixam de ser desempenhados pelo familiar acompanhante. No entanto, dentro do contexto hospitalar esse déficit fica mais acentuado e pode afetar o acompanhante de várias maneiras, já que contribui para um desequilíbrio na própria identidade pessoal, além de modificar as suas expectativas, uso do tempo e a posição dentro do seu grupo social.

O acompanhante deixa de desempenhar suas atividades rotineiras e deixa de viver a sua realidade para entrar num ambiente desconhecido e com características peculiares. $\mathrm{O}$ familiar acompanhante entra no hospital com o paciente e vive, de certa forma, a internação, isto porque, além de acompanhar o paciente, acompanha também a rotina do hospital e da equipe.

Com isso, o familiar acompanhante passa a ser um paciente em potencial para a Terapia Ocupacional, visto que, além de déficits no seu desempenho ocupacional causados pela internaçáo do seu ente querido, vivencia situaçóes geradoras de estresse, medo, preocupação e tristeza. Na prática, é quase unânime os familiares usarem de falas que traduzem suas angústias frente a acontecimentos rotineiros no hospital.

Assim, o ambiente hospitalar deve estar preparado para receber e acolher essa família, devendo considerar suas angústias, ansiedades e sofrimentos como complicadores do processo de cuidar, gerando, se 
não abordados, complicações para ele mesmo e, num aspecto mais global, para o paciente e a família como um todo.

A equipe do hospital deve trabalhar em conjunto para que a necessidade da família seja vista e entendida. Com isso, a comunicação entre familiar, equipe e paciente se fortalece.

Por fim, é de extrema importância que a equipe do hospital olhe para a família como parte importante do processo de convalescência do paciente e que a família se sinta como parceira da equipe. O terapeuta ocupacional da equipe deve buscar entender as dinâmicas que favorecem os cuidados, incentivando a sua organização para que não haja sobrecarga para os acompanhantes ou complicaçóes após a alta hospitalar.

Deve, também, buscar junto à família a elaboração de estratégias para solucionar os possíveis conflitos, com o intuito de ofertar ao paciente os benefícios trazidos pelo acompanhante e tentar, na medida do possível, organizar a família para que ela possa dar suporte social e emocional ao doente.

Além disso, o terapeuta ocupacional deve oferecer um setting no qual o familiar sinta-se a vontade para falar, favorecendo assim a expressáo e verbalização dos sentimentos e promovendo os fatores curativos de grupo. $\mathrm{O}$ acolhimento auxilia na diminuição da ansiedade e melhora a permanência dos acompanhantes no ambiente hospitalar.

O olhar biopsicossocial intrínseco da profissão para o paciente que cuida implica, dentro do contexto hospitalar, em olhar para sua família. Quando a família é auxiliada, cria-se uma via de mão dupla, na qual de um lado tem-se o cuidador na prestação dos cuidados ao paciente, com todos os aspectos que esse papel traz consigo, e, do outro, tem-se a possibilidade de "cuidar de quem cuida", melhorando a sua qualidade de vida e auxiliando na organização familiar.

\section{Referências}

ANDRADE, O. G.; MARCON, S. S.; SILVA, D. M. P. Como os enfermeiros avaliam o cuidado/cuidador familiar. Revista Gaúcha de Enfermagem, Porto Alegre, v. 18, n. 2, p. 123-32, jul. 1997.

BOCCHI, S. C. M. et. al. Family visitors and companions of hospitalized elderly and adults: analysis of the experience from the perspective of the nursing working process. Revista Latino-Americana de Enfermagem, Ribeirão Preto, v. 15, n. 2, p. 304-10, mar./abr. 2007. Disponível em: $<$ http://www.scielo.br/pdf/rlae/v15n2/v15n2a17.pdf>. Acesso em: 07 jul. 2010. http://dx.doi.org/10.1590/ S0104-11692007000200017

CHAGAS, N. R.; MONTEIRO, A. R. M. Educação em saúde e família: o cuidado ao paciente, vítima de acidente vascular cerebral. Acta Scientiarum. Health Science, Maringá, v. 26, n. 1, p. 193-204, 2004. http:// dx.doi.org/10.4025/actascihealthsci.v26i1.1663

DE CARLO, M. M. R. P. et al. Terapia Ocupacional em Contextos Hospitalares. Prática Hospitalar, São Paulo, v. 8, n. 43, p. 158-164, jan./fev. 2006.

DIBAI, M. B. S.; CADE, N. V. A experiência do acompanhante de paciente internado em instituiçáo hospitalar. Revista Enfermagem UERJ, Rio de Janeiro, v. 17, p. 86-90, 2009.

FRANCO, M. C.; JORGE, M. S. B. Sofrimento do familiar frente à hospitalizaçấo. In: ELSEN, I. et al. $O$ viver em família e sua interface com a saúde e a doença. Maringá: EdUEM, 2002. p. 181-198.

HAGEDORN, R. Ferramentas para a prática em terapia ocupacional: uma abordagem estruturada aos conhecimentos e processos centrais. São Paulo: Roca, 2007.

LAUTERT, L.; ECHER, I. C.; UNICOVSKY, M. A. R. O acompanhante do paciente adulto hospitalizado. Revista Gaúcha de Enfermagem, Porto Alegre, v. 19, n. 2, p. 118-131, jul. 1998.

MAXIMINO, V. S. Grupos de atividade com pacientes psicóticos. São José dos Campos: Universidade do Vale do Paraíba, 2001.

PICHON-RIVIÉRE, E. O processo grupal. 7. ed. São Paulo: Martins Fontes, 2005.

ROMANO, B. W. A família e o adoecer durante a hospitalização. Revista da Sociedade de Cardiologia do Estado de São Paulo, Sáo Paulo, v. 7, n. 5, p. 58-62, 1997. Suplemento A.

SILVA, L.; BOCCHI, S. C. M.; BOUSSO, R. S. O papel da solidariedade desempenhada por familiares visitantes e acompanhantes de adultos e idosos hospitalizados. Texto \& Contexto Enfermagem, Florianópolis, v. 17, n. 2, p. 297-303, 2008. http://dx.doi.org/10.1590/ S0104-07072008000200011

VINOGRADOV, S.; YALOM, I. D. Manual de Psicoterapia de Grupo. Porto Alegre: Artes Médicas, 1992.

YALOM, I. D.; LESZCZ, M. Psicoterapia de Grupo: Teoria e Prática. 5. ed. Porto Alegre: Artemed, 2006.

\section{Contribuição dos Autores}

Daniel Ferreira Dahdah: concepção do texto manuscrito, organização de fontes e análises, redação do texto, revisão; Ana Maria Pimenta Carvalho: concepção do texto manuscrito, organização de fontes e análises, redação do texto, revisão; Juliana Carla Delsim: redação do texto, revisão; Bruna Romano Gomes: redaçáo do texto; Vanessa Spera de Miguel: redação do texto 